\title{
PENGEMBANGAN INSTRUMEN TES DRIBBLING PADA OLAHRAGA FUTSAL
}

\author{
Rahma Dewi ${ }^{1}$, Muhammad Taqwa Pakpahan ${ }^{2}$ \\ ${ }^{1}$ Tenaga Pengajar FIK Universitas Negeri Medan \\ ${ }^{2}$ Alumni FIK Universitas Negeri Medan \\ rahmadewi70@yahoo.co.id
}

\begin{abstract}
Abstrak : Penelitian pengembangan ini bertujuan untuk menghasilkan instrumen tes dribbling pada olahraga futsal. Metode penelitian dan pengembangan (Research and Development) ini disertai dengan pendekatan melalui observasi dan wawancara. Subyek dalam penelitian pengembangan ini adalah atlet futsal SMA MULIA, SMK Tritech, SMA Negeri 2 dan SMA Negeri 13 Medan. Instrumen yang digunakan dalam penelitian dan pengembangan ini adalah validitas yang menggunakan validitas ahli dan reliabilitas tes yang menggunakan test re-test dan Uji coba kelompok kecil dan Besar sebagai dasar untuk layak atau tidaknya instrumen yang akan digunakan dalam suatu penelitian. Berdasarkan hasil penelitian dan pengembangan ini dapat disimpulkan bahwa Pengembangan Instrumen tes dribbling pada olahraga futsal sangat dibutuhkan untuk mengetahui kemampuan dribbling pemain futsal, Pengembangan Instrumen tes dribbling pada olahraga futsal yang diciptakan dapat mempermudah pelatih futsal untuk mengetahui kemampuan dribbling pemainnya, dan Pengembangan instrumen tes dribbling pada olahraga futsal sangat dibutuhkan sebagai acuan pelatih sebagai evaluasi dari latihan dribbling pemainnya.
\end{abstract}

Kata Kunci : Analisis Kebutuhan, Instrumen Tes Dribbling Pada Olahraga Futsal

\section{PENDAHULUAN}

Olahraga merupakan gerak tubuh baik dalam aktivitas fisik atau psikis yang berguna untuk menjaga, meningkatkan, dan menyeimbangkan kesehatan jasmani, rohani, dan meningkatkan rasa kebersamaan serta daya saing antar seseorang.

Olahraga tidak hanya sebagai sarana untuk menyehatkan jiwa dan raga tetapi juga mengajarkan bagaimana harus berlaku sportif. Olahraga juga mengajarkan pentinnya kerja sama. Olahraga merupakan wadah untuk mendisiplinkan diri, menekankan pentingnya kerja keras, sabar, teliti, dan menjaga konsentrasi.Futsal merupakan permainan sepakbola yang dimainkan secara beregu yang terdiri dari lima orang dalam satu tim yang dilakukan di dalam ruangan.

Futsal menjadi cabang olahraga yang populer dan digemari oleh seluruh lapisan masyarakat terutama kaum laki-laki mulai dari anak-anak, remaja dan dewasa. Hal tersebut terbukti dari kenyataan yang adadi masyarakat bahwa kebanyakan lebih menyenangi permainan futsal dibandingkan dengan olahraga yang lain. Olahraga futsal merupakan permainan beregu yang populer pada saat ini bahkan telah menjadi permainan nasional di setiap negara. Maraknya perkembangan olahraga futsal ini disebabkan karena cirinya yang memberikan kesempatan pada pemain untuk memperagakan keterampilannya dengan leluasa namun dengan masih tetap berpedoman kepada aturan permainan yang berlaku.

Seperti yang dikemukakan oleh Lhaksana dan Pardosi (2008: 58) bahwa futsal merupakan permainan cepat dengan waktu relatif pendek, serta memiliki ruang gerak yang sempit. Oleh karena itu, kegesitan dan kelincahan mutlak dibutuhkan pemain. Setiap pemain wajib berlari, mengiring, mengoper, dan berusaha memasukkan bola ke gawang lawan.

Layaknya cabang olahraga yang lain, futsal juga harus memiliki standar penilaian untuk masingmasing keterampilan individu seperti, dribbling, passing, shooting dan heading. Keterampilan penting dan mutlak yang harus dikuasai oleh setiap pemain futsal adalah teknik dribbling. Dribbling merupakan kemampuan yang dimiliki setiap pemain dalam menguasai bola sebelum dibebankan kepada temannya untuk menciptakan peluang dalam mencetak gol.

Seperti yang dikemukakan oleh United States Soccer Federation dan Lewis (2000: 61) bahwa, "The most basic of all soccer skills is dribbling. If a player cant't dribble a ball, then he cannot play the game. Every player, including the goal-keeper, must be able to dribble the ball at some level of competency." Hal mendasar dari semua keterampilan sepakbola adalah 
menggiring bola. Jika pemain tidak dapat menggiring bola, maka ia tidak bisa bermain permainan. Setiap pemain termasuk penjaga gawang harus mampu menggiring bola di beberapa tingkat kompetensi.

Peneliti melakukan observasi dan wawancara ke beberapa klub futsal di Kota Medan. Klub futsal pertama yang peneliti observasi adalah Mulia FC yang dilakukan pada hari Sabtu, tanggal 3 September 2016. Mulia FC merupakan suatu wadah untuk berlatih pemain futsal di Kota Medan. Mulia FC merupakan Klub yang memiliki prestasi cukup baik dan dilatih oleh pelatih-pelatih yang berpengalaman. Namun peneliti saat observasi menemukan bahwa untuk mengetahui hasil dari kemampuan dribbling pemainnya, pelatih masih menggunakan instrumen tes dribbling pada olahraga sepakbola.

Observasi kedua di Pembinaan Futsal Universitas Negeri Medan yang dilakukan pada hari Kamis, tanggal 1 Desember 2016. Pembinaan Futsal Universitas Negeri Medan merupakan suatu wadah untuk berlatih pemain futsal khusus mahasiswa Universitas Negeri Medan yang melakukan latihan setiap hari di Lapangan Futsal Universitas Negeri Medan. Saat observasi peneliti menemukan bahwa Pembinaan Futsal Universitas Negeri Medan masih menggunakan instrumen tes dribbling olahraga sepakbola untuk mengetahui hasil dari kemampuan dribbling para pemainnya. Tentunya hasil yang didapat tidak akan maksimal dan akurat, dikarenakan ukuran, berat, permukaan lapangan dan pantulan yang dihasilkan dari bola futsal dan bola yang digunakan pada olahraga sepakbola sangat jauh berbeda.

Observasi ketiga di SMA Negeri 13 Medan yang dilakukan pada hari Senin, tanggal 12 Desember 2016. SMA Negeri 13 Medan merupakan salah satu sekolah yang berprestasi dalam olahraga futsal. Pada saat melakukan observasi peneliti menemukan bahwa pelatih futsal SMA Negeri 13 Medan masih belum mengukur hasil kemampuan dribbling para pemainnya. Selama ini pelatih mengukur kemampuan dribbling pemainnya hanya dengan melihat proses selama latihan berlangsung.

Fenomena di Fakultas Ilmu Keolahragaan Universitas Negeri Medan juga menjadi alasan perlunya dilakukan pengembangan instrumen tes dribbling pada olahraga futsal, hal tersebut terlihat dari banyaknya mahasiswa yang pada saat permohonan judul skripsi menolak untuk melakukan penelitian pengembangan tentang olahraga futsal. Hal tersebut disebabkan tidak adanya norma yang baku untuk cabang olahraga futsal.

Hasil wawancara yang diperoleh dari pelatih futsal bahwa mereka sangat membutuhkan instrumen tes dribbling pada olahraga futsal karena sampai saat ini untuk mengukur hasil kemampuan dribbling pada olahraga futsal masih menggunakan instrumen tes olahraga sepakbola. Berdasarkan analisis kebutuhan maka peneliti ingin mengembangkan instrumen tes dribbling pada olahraga futsal untuk mempermudah pelatih menilai kemampuan dribbling para pemainnya.

\section{METODE}

Penelitian dilaksanakan di lapangan futsal tempat sekolah yang diteliti. Waktu penelitian dilaksanakan pada 12 Desember 2017. Penyusunan sampel uji coba pada penelitian ini dengan tahap uji coba tahap I (uji coba produk) dan uji tahap II (uji coba pemakaian) ditujukan pada tiga sekolah yaitu SMA Negeri 13 Medan, SMA Negeri 2 Medan, SMK Tritech dan SMA Mulia.

Metode yang digunakan pada penelitian ini adalah penelitian pengembangan produk, menguji keefektifan produk yang mencapai tujuan yang diinginkan. Hasil akhir dari kegiatan penelitian dan pengembangan ini adalah pengembangan instrumen tes dribbling pada olahraga futsal yang dapat membantu pelatih dan pemain futsal dalam latihan futsal khususnya untuk teknik dribbling.

\section{Langkah-langkah Pengembangan Model}

\section{Penelitian Pendahuluan}

Penelitian pendahuluan dilakukan untuk mendapat analisis kebutuhan. Hasil wawancara dengan pelatih mengatakan bahwa instrumen tes dribbling pada olahraga futsal sangat dibutuhkan sehingga dapat digunakan untuk mempermudah pelatih menilai kemampuan dribbling pemainnya. Pelatih menginginkan adanya pengembangan instrumen tes untuk membantu jalannya program latihan dan semakin banyaknya minat masyarakat untuk bermain futsal dan agar mempermudah pelatih untuk melakukan seleksi kemampuan setiap pemain. Maka dapat disimpulkan bahwa perlu adanya pengembangan instrumen tes dribbling pada olahraga futsal.

\section{Perencanan Pengembangan Model}

Perencanan dan penyusunan dibuat agar dapat memberikan tuntutan secara jelas dalam pelakasanaan penelitian pengembangan. Perencanaan dan penyusunan model terkait dengan strategi yang akan direncanakan dan disusun secara sistematis.

Penelitian ini menggunakan metode Penelitian dan Pegembangan (Research and Development) dari Borg dan Gall, model ini dipilih karena prosedur yang dikembangkan Borg dan Gall lebih lengkap karena memiliki dua tujuan utama yaitu: (1) mengembangkan produk, dan (2) menguji keefektifan produk dalam mencapai tujuan yang akan dicapainya. Berdasarkan pendapat tersebut maka pada konteks penelitian ini, hanya diambil langkah tahap yang relevan untuk memberikan pengembangan instrumen tes dribbling pada olahraga futsal bagi setiap para pelatih dan pemain. 


\section{Desain Produk Draf Awal}

Lapangan yang digunak untuk mengukur tes ini adalah lapanga futsal yang terbuat dari bahan interlock, parquette, vinyl, dan semen.

a) Lapangan tes Dribbling dilakukan sebanyak 1 set melewati kun A, B, C, D, E, F, G dan kembali lagi, yang dimulai dari kun G, F, E, D, C, B, A.
A-B : Melakukan dribble dibagian luar marker.

B-A : Melakukan dribble dibagian luar marker.

A-C : Melakukan dribble dibagian luar marker.

$\mathrm{C}-\mathrm{A}$ : Melakukan dribble dibagian luar marker.

A-D-E-F-G : Melakukan dribble zig-zag.

G-F-E-D-A : Melakukan dribble zig-zag.

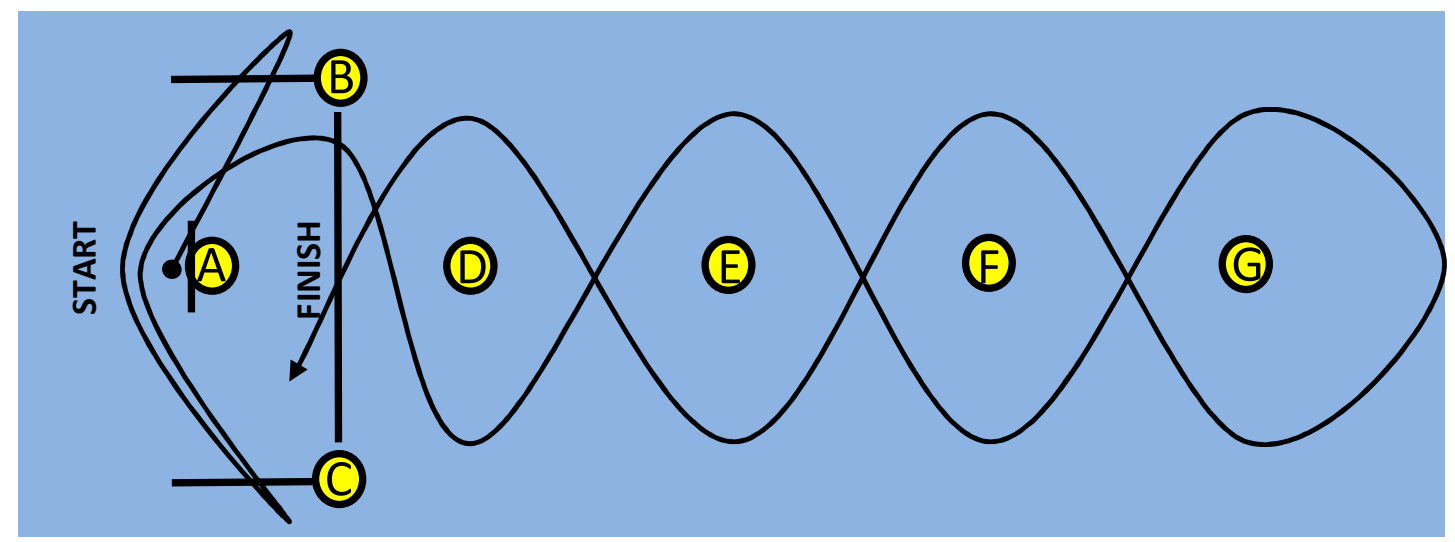

Gambar 1. Draft Awal (Desain Peneliti)

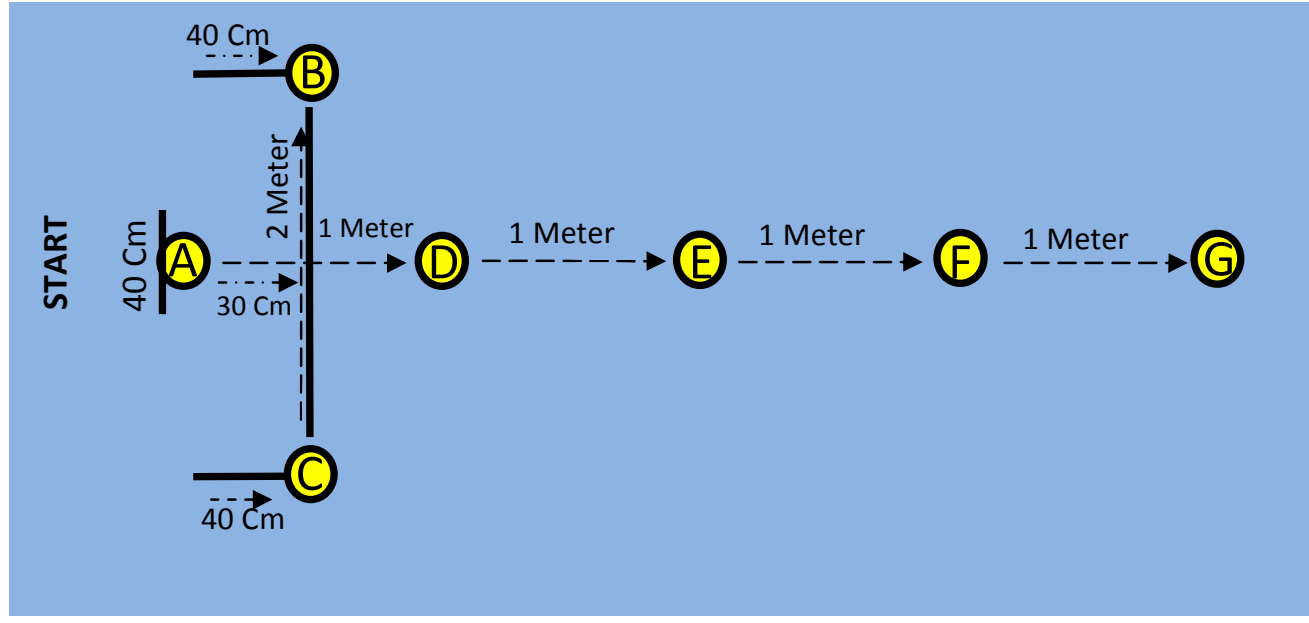

Gambar 2. Ketentuan Ukuran Marker

\section{Catatan :}

a) Perhitungan ukuran dimulai dari tepi marker.

b) Menentukan letak marker $\mathrm{B}$ dan $\mathrm{C}$ yaitu dengan membagi rata ukuran antara marker $\mathrm{A}$ dan $\mathrm{B}$, kemudian dari titik tengah antara marker A dan B di ukur jarak 1 meter kearah marker B dan kearah marker C, sehingga jarak antara marker $\mathrm{B}$ dan $\mathrm{C}$ adalah 2 meter.

\section{Validasi, Evaluasi dan Revisi Model}

Pengembangan instrumen tes dribbling pada olahraga futsal akan divalidasi oleh ahli yang sudah ditentukan yaitu Fandi Frima Dana Butarbutar, Argubi Silwan M.Pd, dan Dr. Imran Akhmad, M.Pd.
Untuk uji reliabilitas, peneliti menggunakan teknik test re-test (tes ulang), sehingga instrumen tes dribbling pada olahraga futsal akan diuji cobakan dua kali kepada sampel uji coba yang sama. 


\section{HASIL DAN PEMBAHASAN}

Hasil pengujian reliabilitas dengan menggunakan test - retest yang dilakukan dengan menggunakan data kecepatan di tes kedua pada hari pertama terhadap tes yang kedua pada hari ke dua. Dari hasil analisis diperoleh nilai $\mathrm{r}$ sebesar 0,8912 yang berarti mempunyai reabilitas yang kuat atau bereabilitas tinggi.

Validitas dapat dikoreksi melalui analisis daya pembeda dengan menggunakan uji-t dengan persentase $27 \%$ dengan terlebih dahulu merata- ratakan nilai test dan nilai retest. Terlebih dahulu kedua data (tes kedua hari pertama dan tes kedua hari kedua) yaitu data kecepatan dirata-ratakan baru diurutkan dari angka tertinggi hingga terendah, selanjutnya diambil data dari atas dan bawan masingmasing 27\%. Menghitung $27 \%$ adalah $\frac{27}{100} \times 30=$ 8,1 dibulatkan menjadi 8 .

Jadi, 8 jawaban yang digunakan dalam menganalisis daya pembeda untuk mendapatkan nilai $t_{\text {hitung. }}$ Nilai $t_{\text {tabel }}=2,365$. Jadi $t_{\text {hitung }}>t_{\text {tabel }}$ $(8,35>2,365)$, disimpulkan bahwa data tersebut valid.

Tabel 1. Kategori Norma

\begin{tabular}{|c|c|c|c|}
\hline Batas Skor & $\begin{array}{c}\text { Waktu } \\
(\text { Detik })\end{array}$ & Nilai & Kategori \\
\hline $13,86+(1,5 \times 1,30)$ & 15,81 & E & Kurang Sekali \\
\hline $13,86+(0,5 \times 1,30)$ & 14,51 & D & Kurang \\
\hline $13,86-(0,5 \times 1,30)$ & 13,21 & C & Sedang \\
\hline $13,86-(1,5 \times 1,30)$ & 11,91 & B & Baik \\
\hline $13,86-(1,5 \times 1,30)$ & 11,91 & A & Baik Sekali \\
\hline
\end{tabular}

Tabel 2. Norma Kecepatan Dribbling

\begin{tabular}{|l|c|}
\hline \multicolumn{1}{|c|}{ Kategori } & Waktu (Detik) \\
\hline Baik Sekali & $<11,91$ \\
\hline Baik & $11,91-13,20$ \\
\hline Sedang & $13,21-14,50$ \\
\hline Kurang & $14,51-15,80$ \\
\hline Kurang Sekali & $>15,80$ \\
\hline
\end{tabular}

Setelah produk direvisi maka selanjutnya dilakukan uji coba kelompok kecil kepada 10 pemain untuk melihat keefektifan produk instrumen tes dribbling dan diamati para ahli atau pelatih futsal dan ahli olahraga.

Hasil data yang diperoleh dari para ahli/pelatih futsal dan ahli olahraga maka peneliti menyimpulkan bahwa produk instrumen tes dribbling yang dikembangkan mendapat respon positif dari para ahli. Data yang diperoleh dari ahli/ pelatih futsal, dan ahli olahraga dapat disimpulkan sebagai berikut :

a) Produk yang dikembangkan diharapkan agar dapat diberikan kepada para pelatih futsal dengan harapan dapat digunakan untuk mendapatkan hasil dribbling yang baik. b) Dengan adanya produk baru ini diharapkan dapat memperbaiki kualitas para pemain futsal.

Proses penyempurnaan produk dilakukan melalui beberapa tahapan yaitu dimulai dari pembuatan draft awal setelah peneliti membuat draft awal lalu peneliti berkonsultasi kepada pelatih futsal, berikutnya dilakukan evaluasi dari ahli kemudian peneliti merevisi produk tersebut sehingga sudah siap untuk di uji cobakan pada tahap I yaitu uji coba kelompok kecil 10 pemain.Pada pelaksanaan uji coba tahap I uji coba kelompok kecil peneliti memperoleh data dari pernyataan dan saran ahli menghasilkan penyempurnaan produk instrumen tes dribbling dalam permainan futsal. Berdasarkan hasil dari kesimpulan peneliti memperbaiki kembali produk ini untuk tahap penyempurnaan sehingga produk ini 
layak untuk di uji cobakan pada tahap II uji coba kelompok besar. Setelah dilakukan uji coba tahap II diiringi proses revisi tahap II maka disimpulkan bahwa produk ini sudah layak untuk dijadikan instrumen tes dengan harapan dapat menjadi alat ukur bagi setiap pelatih saat melatih pemainnya.

Pengembangan produk ini bertujuan untuk menciptakan instrumen tes dribbling yang belum dibakukan sampai saat ini. Produk yang dikembangkan ini didasari dengan adanya kebutuhan para pelatih dan pemain yang sampai saat ini belum bisa mengukur hasil dribbling dalam permainan futsal.

Berdasarkan pembahasan pengembangan produk instrumen tes dribbling yang dilakukan memiliki keunggulan:

1. Pelatih lebih mudah untuk mengetahui kemampuan dribbling atlet mereka.

2. Atlet lebih termotivasi untuk meningkatkan kemampuan dribbling setelah mengetahui hasil tes kemampuan mereka.

Penelitian dan pengembangan ini memiliki beberapa keterbatasan. Keterbatasan dalam penelitian pengembangan ini adalah sebagai berikut:

1. Dikarenakan waktu pelaksanaan uji coba dan penelitian ini bersamaan dengan liga AAFI (Asosiasi Akademi Futsal Indonesia), peneliti mengalami kesulitan pada saat akan melakukan penelitian dan uji coba lapangan, hal itu dikarenakan dalam program pelatih tidak lagi melakukan tes untuk mengetahui kemampuan dribbling atletnya.

2. Penelititan yang dilakukan hanya dilakukan pada SMK Tritech, SMA Negeri 3 Medan dan SMA Negeri 2 Medan, maka umumnya penelitian hanya dapat di lakukan dengan populasi yang memiliki karakter yang sama dengan sampel yang diteliti.

3. Sampel yang diteliti dalam penelitian ini merupakan siswa yang aktif di sekolah dan juga aktif di klub atau di akademi futsal masingmasing, sehingga ada kesulitan untuk menyatukan mereka pada saat melukan uji coba lapangan.

\section{KESIMPULAN}

Berdasarkan hasil penelitian dan pengembangan ini dapat disimpulkan bahwa:

1. Pengembangan Instrumen tes dribbling pada olahraga futsal sangat dibutuhkan untuk mengetahui kemampuan dribbling pemain futsal.
2. Pengembangan Instrumen tes dribbling pada olahraga futsal yang diciptakan dapat mempermudah pelatih futsal untuk mengetahui kemampuan dribbling pemainnya.

3. Pengembangan instrumen tes dribbling pada olahraga futsal sangat dibutuhkan sebagai acuan pelatih sebagai evaluasi dari latihan dribbling pemainnya.

\section{SARAN}

Berdasarkan hasil penelitian dan pengembangan ini, maka dapat disarankan hal-hal sebagai berikut:

1. Hasil pengembangan instrumen tes dribbling pada olahraga futsal ini diharapkan dapat berguna sebagai acuan para pelatih-pelatih futsal, untuk melihat sejauhmana perkembangan kemampuan dribbling pemainnya.

2. Mengingat hasil produk penelitian dan pengembangan instrumen tes dribbling pada olahraga futsal dapat memberikan manfaat untuk hasil latihan, maka disarankan untuk mencetak dan menyebar luaskan produk menjadi banyak, agar dapat dimanfaatkan secara lebih luas

3. Perlunya pengembangan lebih lanjut guna meningkatkan kualitas dari instrumen tes dribbling pada olahraga futsal, disarankan pengembangan yang dilakukan disesuaikan dengan perkembangan teknologi yang ada, guna mendapatkan hasil yang akurat dengan menggunakan teknologi yang lebih maju.

\section{REFERENSI}

Ainamulyana.2016.http://ainamulyana.blogspot.co.id /2016/04/penelitian-pengembanganresearchand.html?m=1.(diakeses: 21 Juni 2016).

Arikunto, Suharsimi. 2012. Dasar-dasar Evaluasi Pendidikan. Jakarta: Bumi Aksara.

Futsallife. 2016. http://www.futsalife.com/7-manfaatbermain-futsal/. (diakses: 22 Juni 2016).

Gifford, Clive. 2007. Keterampilan Sepakbola. Yogyakarta: Citra Aji Paramana.

Lhaksana, Justinus. 2011. Taktik dan Strategi Futsal Modern. Jakarta: Be Champion.

Lhaksana, Justinus. dan Pardosi, Ishak H. 2008. Inspirasi dan Spirit Futsal. Jakarta: Raih Asa Sukses. 
Mielke, Danny. 2007. Dasar-Dasar Sepakbola. Bandung: Pakar Raya.

Murhananto. 2008. Dasar-Dasar Permainan Futsal. Jakarta: Kawan Pustaka.

Nazir, Moh. 2011. Metode Penelitian. Bogor: Ghalia Indonesia.

Rakasiwi, Putri Agil. dkk. 2013. Developing Futsal Test Digital Media in Yogya FIK Futsal by Using Macromedia Flash. Jurnal Universitas Negeri Yogyakarta. Volume III. Nomor 1. April 2013.

Sudijono, Anas. 2011. Pengantar Evaluasi Pendidikan. Jakarta: Rajawali Pers.
Sugiyono. 2015. Metode Penelitian Pendidikan (Pendekatan Kuantitatif, Kualitatif, dan $R \& D)$. Bandung: Alfabeta.

Sukmadinanta, Nana Syaodih. 2012. Metodologi Penelitian Pendidikan. Bandung: Remaja Rosdakarya.

United States Soccer Federation, Inc. and Lewis, Michael. 2000. Soccer for Dummies. New York: Wiley Publishing, Inc.

Wikipedia. 2016. https://id.m.wikipedia.org/wiki/ Futsal. (diakses: 21 Juni 2016) 